\title{
Beyond the workforce training pipeline: embracing the meandering stream of "whole of life" and career to strengthen the retention of health professionals rurally
}

\author{
Richard Colbran
}

NSW Rural Doctors Network, Newcastle, Australia

Robyn Ramsden

School of Health and Social Development, Deakin University, Victoria, Australia

Michael Edwards

Information and Translation, NSW Rural Doctors Network,

Newcastle, Australia, and

Emer O'Callaghan and Dave Karlson

NSW Rural Doctors Network, Newcastle, Australia

\begin{abstract}
Purpose - While Australia has continued to invest in polices and strategies aimed at improving rural health service provision, many communities still confront a disproportionate share of the rural workforce shortage. The NSW Rural Doctors Network (RDN) contributes its perspectives about the importance of a whole of life career and the meandering stream concept to support the retention of health professionals rurally. We unpack these concepts and examine how they bring to light a new and useful approach to addressing rural workforce challenges and potentially contribute to building a stronger integrated care approach.

Design/methodology/approach - The approach used involved tapping into RDN's 30-years of experience in recruitment and retention of remote and rural health professionals, combined with insights from relevant existing and emerging evidence.

Findings - We suggest that reframing retention to consider a life stage approach to career will guide more effective targeting of rural health policies, workforce planning, collaborative approaches and allocation of incentives. We posit that an understanding and acceptance of modern lifestyles and career pathways, and a celebration of career commitment to serving rural communities, is necessary for successful recruitment and retention of Australia's future rural health workforce beyond the training pipeline.
\end{abstract}

C Richard Colbran, Robyn Ramsden, Michael Edwards, Emer O'Callaghan and Dave Karlson. Published by Emerald Publishing Limited. This article is published under the Creative Commons Attribution (CC BY 4.0) licence. Anyone may reproduce, distribute, translate and create derivative works of this article (for both commercial and non-commercial purposes), subject to full attribution to the original publication and authors. The full terms of this licence may be seen at http://creativecommons.org/licences/by/4.0/ legalcode

We thank Dr Charles Evill and the Rural Doctors Association (NSW) for the useful discussions and Tom Hutton for his design work on the Meandering Stream Model diagram.
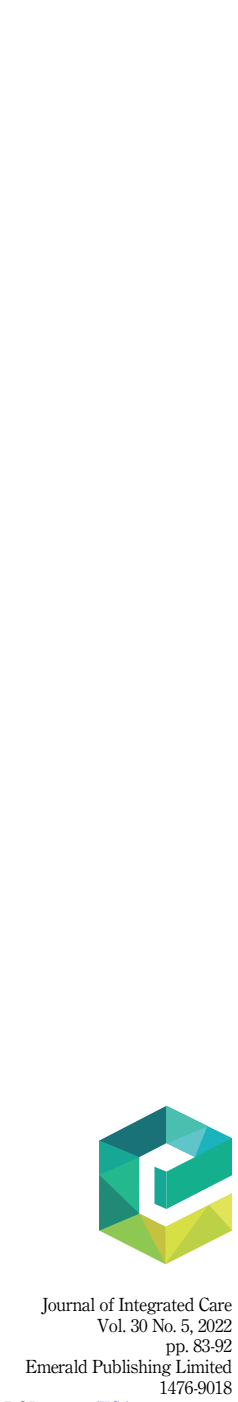
JICA

30,5

Originality/value - We outline and visually represent RDN's meandering stream approach to building and retaining a capable rural health workforce through addressing life cycle and workforce level needs. This perspective paper draws on RDN's direct experience in the field.

Keywords Rural health care, Rural health professionals, Rural recruitment, Rural retention, Life stage approach, Whole of life, Integrated care

Paper type Viewpoint

\section{4}

\section{Introduction}

Lack of access to quality health care providers is one of the primary root causes of health inequity globally and is disproportionately experienced by people living in remote and rural communities (WHO, 2010). Residents of rural and remote Australia also have poorer health outcomes compared to their metropolitan counterparts (AIHW, 2019). Sustaining an adequate, appropriately qualified health workforce is a key element for ensuring the provision of accessible, comprehensive, high-quality Primary Health Care (Buykx et al., 2010; Humphreys et al., 2007). However, despite efforts to address this disparity, it remains a challenge to attract and retain health professionals motivated to work in rural locations in Australia and elsewhere (AIHW, 2019; Durey et al., 2015). In a study of workforce turnover and retention in remote communities in the Northern Territory, Wakerman et al. (2019) found that only $20 \%$ of remote area nurses and allied health professionals (AHPs) remained working at the same remote clinic 12 months after commencing (RANs 19\%, AHPs $27 \%$ ); half left within 4 months. The NSW Rural Doctors Network (RDN), a 30-year-old independent, non-governmental organisation responsible for supporting the attraction, recruitment and retention of a capable primary health care workforce in rural NSW found that the average tenure of rural GP's was approximately 5 years (NSWRDN, 2018). Rural GPs practising in small towns (less than 5,000 residents) and in medium-sized towns (up to 15,000 residents) were most at risk of moving to metropolitan areas (Humphreys et al., 2012; McGrail and Humphreys, 2009).

In the literature, retention refers to some minimum length of stay, rather than implying indefinite length of service in one location, employer or organisation (Durey et al., 2015; Humphreys et al., 2007). RDN has as a broader notion of retention that involves commitment to working in rural health (whatever form it takes), not just within one location, organisation or employer. The field of health professionals includes those who work as general practitioners, specialists, nurses, midwives, dentists, Aboriginal health practitioners and allied health professionals.

Multiple approaches, programs and policies have been implemented in an attempt to meet and overcome the challenges associated with the retention of health professionals (Bukyx et al., 2010). Integrated health care has been identified as an important approach for improving continuity and coordination of care (Rygh and Hjortdahl, 2007), addressing the challenges of health care delivery and achieving better patient outcomes for people living in rural and regional areas (May, 2015). It also provides the foundation to link rural and remote workforce initiatives into the achievement of broader health workforce priorities and functional (profession specific) workforce plans (Queenland Health, 2017). Given health professionals' involvement in all aspects of integrated care delivery, changes to the rural health workforce bought about by factors such as workforce mobility and shortage, affect the implementation of integrated care profoundly (Busetto et al., 2018; Fitzpatrick et al., 2018). Therefore, we argue it is important to not only focus on strategies for integration activities but also on the people who need to implement and utilise the plethora of tools and instruments to support and foster integration of health and social services, (Stein, 2016). This perspective paper proposes the type of conditions that might support rural workforce retention and in doing so contribute to building a stronger integrated care approach. 
The idea of rural pipeline emerged as a multifaceted, integrated sequence of tailored interventions over time to support a health professional develop as a motivated and welltrained rural health practitioner (Bell, 2011; Buykx et al., 2010). While retention is often discussed in the literature as a key stage of the rural pipeline (for example, Henry et al., 2009), it generally refers to education and professional support for health professionals to remain in rural practice (Geyman et al., 2008; Norris, 2005). Once employed in rural locations, retention strategies are needed to increase duration in the rural area and reduce staff turnover (Humphreys et al., 2009).

It is clear that professional and personal differences along the career pathway create a need for retention strategies that are multifaceted and "bundled" to ensure they closely target the combination of factors important for the retention of specific groups of health professionals (Bukyr et al., 2010; Russell et al., 2017). Cosgrave et al. (2019) argue the majority of rural health recruitment and retention research has focused on recruitment influences relating to the medical workforce. Further, Battye et al. (2019) note that the evidence for the efficacy of retention strategies for allied health professionals in rural areas is limited across individual professions or for allied health professionals as a whole, largely due to issues with research design.

It has been identified in the literature that strategies need to target social and professional factors including differential needs for age, discipline, gender, career stage, nature of work and location (Allen et al., 2020; Durey et al., 2015; Humphreys et al., 2010; McGrail and Humphreys, 2015). Wakerman et al. (2019) noted the importance of addressing health system issues that ensure a safe and supportive work environment, and a clear, supported career pathway including post-graduate and continuing professional development support, with flexible entry and exit points. Cosgrave et al. (2018) and Cosgrave (2020) suggested that place-based social processes should be identified and a depth of understanding about individual/family unit contexts and social situations that heighten turnover risk fostered before appropriate responses and supports can be designed. Richards et al. (2005) highlighted the importance of addressing concerns about educational opportunities for children and considering proximity to extended family and social circles. Consideration of children's education and proximity to extended family are two examples aligned with life stages. In a study of allied health professionals, Cosgrave et al. (2018) argued that life stage, rather than rural origin, is the major determinant of turnover, and that those in early adulthood (usually in their early-to-mid 20s) were the most likely to leave within a couple of years of working, regardless of background. Studies by Alexander (1998) and Ballance et al. (2009) report the importance of work/life balance where health practitioners require appropriate facilities to meet their "quality of life" needs.

RDN refers to life balance rather than work/life balance as work is part of life and believes that the days of living in one town or having one job for an entire career are no longer the central tenet of a successful rural career. Taking it a step further, RDN suggests looking to the whole of life in the consideration of strategies to retain health professionals in a rural career, even if not in the same town or with the same employer. The whole of life concept embraces work, but also the stages through which life and career progress. The authors suggest the term meandering stream more accurately describes the non-linear post training career pathway and provides a lens through which to consider ways to encourage health professionals to stay working rurally throughout their career.

This perspective paper explains the concepts of whole of life and meandering stream and how these concepts may improve retention of rural health professionals. The paper also provides a visual representation and explanation of RDN's approach to building a highly capability rural health workforce using the meandering stream concept. 
JICA

30,5

86

\section{What is a whole of life career?}

RDN posits that a focus on a whole-of life career pathway is fundamental to addressing the rural retention challenge. Our experience is that the career needs of health professionals change over their life cycle and different strategies and levels of support are needed throughout to encourage them to stay rural. A study by Hancock et al. (2009) dealing with rural-based physicians in the USA which investigated physicians' practice location choices over their life course, observed that apart from desiring place and community integration, living a happy and satisfying life was an important motivation. Therefore, it is important to help develop appropriate retention goals and strategies to improve personal satisfaction tailored to individuals' lives and career-stage.

Drawing on the place-based social processes work of Cosgrave et al. (2018), retention strategies should also consider recruitment to a rural place that suits the health practitioners' stage of life and career with the option to vary that placement should the health practitioner's stage of life require it. We suggest there is advantage in not losing health professionals with rural experience, but to retain their expertise rurally to help achieve better quality and more efficient health care delivery. Cosgrave (2018) developed a "whole-of-person" retention framework that outlines factors to improve professional and personal satisfaction of health professionals across three key life domains - organisational, career building alongside community and place. We add that it is also important to consider a person's whole of life and career circumstances and find health professional centred retention strategies to engage and retain a health professional in rural areas throughout their career. A rural health workforce career means different things to different people and this needs to be understood if we are to retain health professionals. In practice, this would involve matching health professionals with a rural location, in a style of rural practice, or with work conditions that suit their current lifestyle. This more holistic approach might help to broker honest conversations about the intentions of health practitioners to enable them to contribute to the current circumstance, while facilitating and planning for their next move. Retention strategies should be sufficiently flexible to meet the needs of health professionals working in different contexts and to sustain life balance. The critical mindset is to look at ways to retain a health professional in rural practice rather than to exclude them because they do not fit with traditional ways of fulfilling role and managing lifestyles. This may even involve them leaving rural practice for a regional or metropolitan setting, but returning when it suits their life stage, or continuing to contribute knowledge and expertise even after they have retired.

\section{What is a meandering stream and why is it important?}

There is a need for more personalised conceptualisations of retention that reflect, in particular, a life-stage perspective on likely duration of stay (Cosgrave et al., 2019). We liken that personalised conceptualisation to that of a meandering stream (Figure 1). River meandering is a well-studied subject in fluvial morphology with a long history of literature about the cause, processes and prediction of meandering (Schuurman et al., 2016). A meander is one of a series of regular sinuous curves, bends, loops, turns, or windings in the channel of a river, stream or other watercourse. As water flows around these curves, the outer edge of water is moving faster than the inner. The increased speed leads to increased erosion and the bend becomes wider. As the bend becomes wider the overall length of the stream increases (A level Geography, 2019; One Geology, 2019).

There are several relevant metaphors in this description. It speaks to the twists and turns that a health career inevitably takes over a lifetime and the opportunity to take a change in direction or to slow down from the frenetic pace at times. It highlights the need for depositing into one's professional, educational, personal, social and emotional bank accounts to sustain a health professional in the rural network and to offset the erosions caused through long hours 

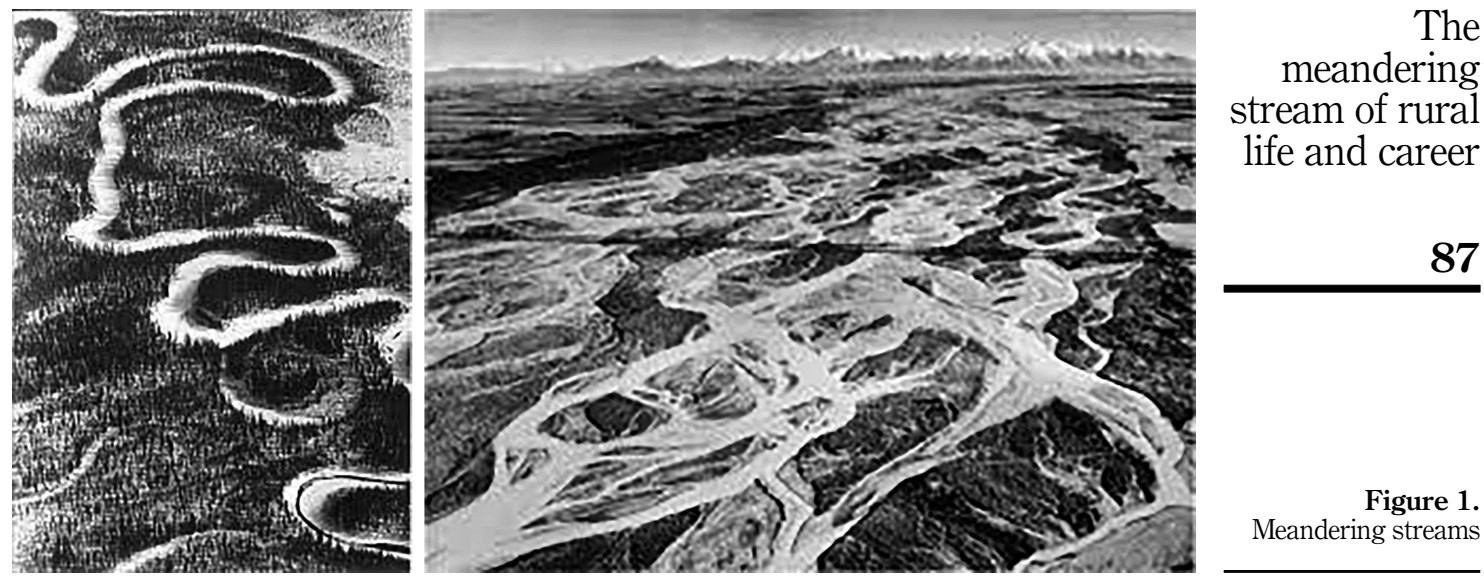

of service and work burnout. The increase in length of the stream as it meanders is a metaphor for retaining a health professional in a rural health career for a longer period of time.

The meandering stream concept provides opportunity to use and develop retention strategies that reflect the various stages of career practice with differences in age, gender, professional needs, social contact and cultural background. Figure 2 outlines RDN's blueprint for creating a highly capable rural health workforce. We think helping to support a health practitioner be capable can help them to be adaptable, feel motivated and thus have resilience to stay through "tough times" which is necessary in a long career in rural health (Martiniuk et al., in press). Where health professionals stay working rurally for longer there is the potential to strengthen communication, both professionally and with patients. As Dawda (2019) points out, connectivity, collaboration and alignment have the potential to deliver better integrated primary healthcare experiences and outcomes for patients.

\section{The theoretical/conceptual model}

The Model (Figure 2) outlines the career pathway of a health professional from joining the pool of rural health professionals to retirement and identifies the influences on rural retention. It shows the services and supports that are inputted at various stages through the career lifecycle. The nature and balance of those supports and services along the continuum changes according to need and lifestyle factors impacting, including community relationships, environment, family lifestyle factors, availability of professional support, work variety and workload. That is, different types of services and supports are required at different points along the stream with the dynamic balance of evolving influences and work life considerations.

We also suggest the meandering stream, whole of life career perspective is helpful in considering how to retain a health professional for the whole of their career rurally and the positive impact that might have on delivering high quality primary health care. Much of the discussion and literature has been about how long it is possible to retain a health professional in one town or one service to sustain a viable and capable health workforce in that town, rather than about how to retain them rurally throughout their career, or to entice them back after a break. Rather than only focus on workforce stability in a town or service, we think it is also important to consider health professionals life stages and pathways more closely and 
JICA

30,5

88

Figure 2.

The meandering stream approach

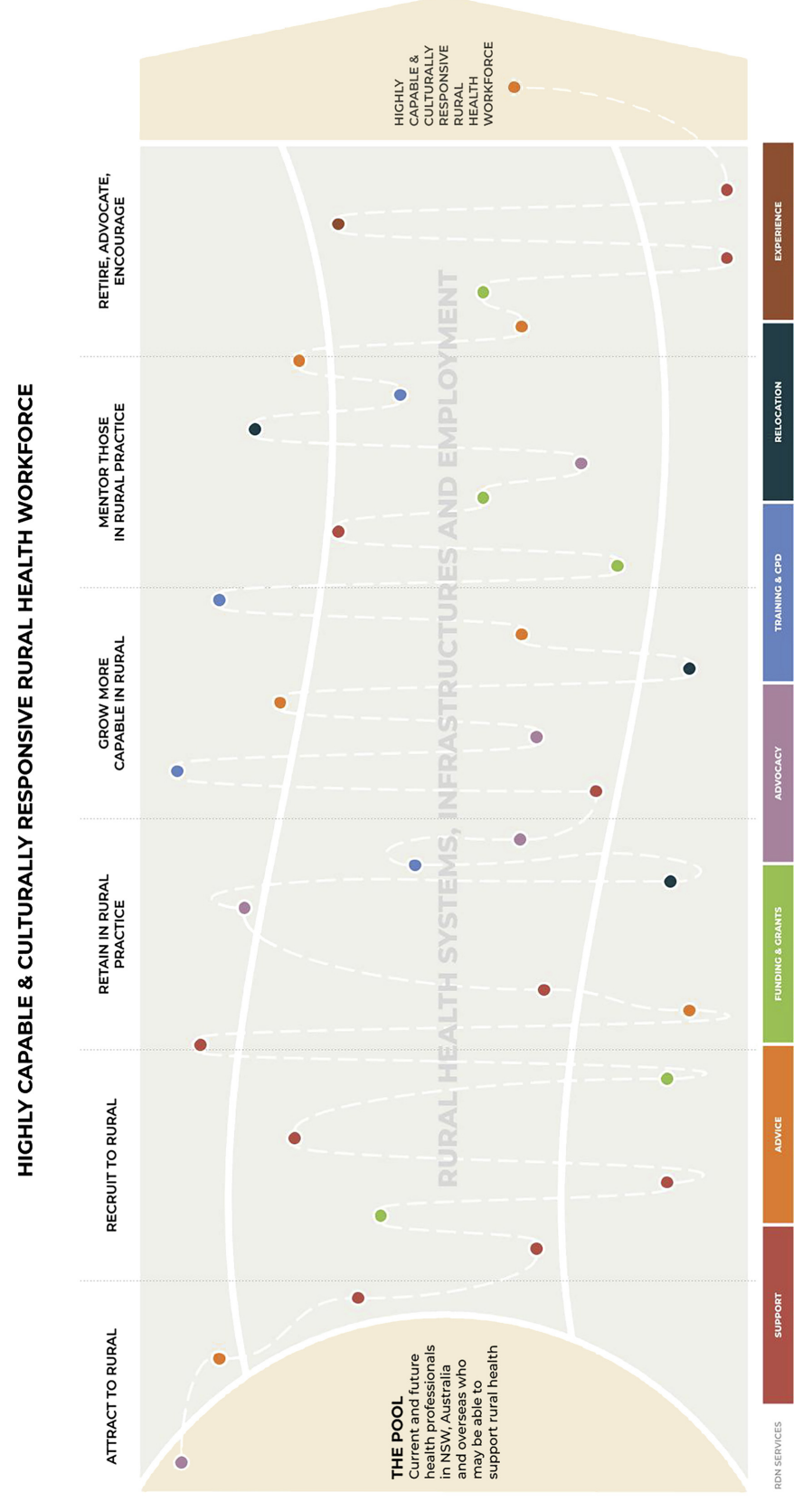


provide strategies and supports to suit. Thinking beyond a solution for a rural town, this concept means we understand and help support the life stage needs of health professionals and in that way foster the vibrancy of the stream for others downstream. This embraces the idea that the right health professionals are available where and when they are needed and are able to seek careers opportunities in a flexible and adaptive manner to meet their life stage needs as well as those of rural patients. We want health professionals to dedicate and celebrate working rurally throughout their careers. RDN has found through health outreach and other programs and its Health Workforce Needs Assessment, that being adaptive to the health practitioners needs and the various place-based and cultural contexts helps to retain a health professional rurally (NSWRDN, 2019), although this is as yet scientifically untested.

If health professionals and communities embrace this concept, it may positively influence health professionals to consider staying rural as their needs change. This is an extension of the Easy Entry Gracious Exit model RDN created in the 1990s, which has proven to be effective in attracting and retaining doctors (NSWRDN, 2003). The approach concentrated on the continuity of the service rather than the continuity of the doctor to give them the freedom to leave, hoping that the experience would be attractive enough to entice them to stay for a reasonable period. The whole of life career pathway and meandering stream concepts are also designed to enable a gracious exit from a location, service or organisation, but provide encouragement to stay working rurally or to return when their life stage permits. To facilitate this, it is important that from the moment of engagement with each health professional, the barriers that might be associated with exiting a town are removed (Lynch, 2003; Wakerman et al., 2006), and that a sense of inclusion is fostered. RDNs experience has been that each interaction with a health professional has an impact, as a sector, on the available pool of people to work rurally.

RDN acknowledges the importance of partnership with other health services, governance bodies, the education and training sector and communities to ensure the gains being made are not lost. It is essential to utilise the valuable contributions of those in the field, who know the environment and can broker relationships to ensure that exclusionary approaches are not created or to bring the broader thinking about this approach. It is also important to know when to intervene and at what points along the meandering stream.

\section{Conclusion}

It is clear that many factors contribute to how long health professionals stay in their jobs and that no single measure is likely to improve retention significantly if other important factors prompting people to leave are not also addressed. In this paper, we advocate the need to embrace contemporary thinking about what health professionals require across the life cycle to support their rural career. We explore the concept of the meandering stream of life and career and its potential to address retention issues. Recruiting health professionals into a rural health position is not enough. We recommend nurturing and supporting health professionals' diverse needs over their entire career to retain them or to entice them back to rural practice. Reframing the concept of rural workforce ensures that rural communities are at the centre of the vision. While the insights we have gained from working in the field have provided a useful guide for action and influenced the development of the whole of life and meandering stream concepts, it is hoped these can make a valuable contribution more broadly to policy makers, service providers, practitioners and communities. It is important that we do not see the RDN meandering stream approach as an endpoint, but an opportunity to continue to explore and add depth to the ideas proposed. While it could be a valuable tool with wider application, it needs to be tested through research. Further, given that a strong and stable health workforce has the potential to enhance integrated rural primary health care in rural communities, these are also important areas for greater exploration. 
JICA

30,5

\section{References}

A Level Geography (2019), Meanders, A Level Geography, available at: https://www.alevelgeography. com/meanders/ (accessed 6 March 2020).

Allen, P., May, J., Pegram, R. and Shires, L. (2020), “It's mostly about the job' - putting the lens on specialist rural retention", Rural and Remote Health, Vol. 20, p. 5299, doi: 10.22605/RRH5299.

Alexander, C. (1998), "Why doctors would stay in rural practice in the New England health area of New South Wales", Australian Journal of Rural Health, Vol. 6 No. 3, pp. 136-139.

Australian Institute of Health and Welfare (2019), "Rural and remote health—web report", available at: https://www.aihw.gov.au/reports/rural-health/rural-remote-health/contents/rural-health (accessed 16 March 2020).

Balance, D., Kornegay, D. and Evans, P. (2009), "Factors that influence physicians to practice in rural locations: a review and commentary", Journal of Rural Health, Vol. 25 No. 2, pp. 76-81.

Battye, K., Roufeil, L., Edwards, M., Hardaker, L., Janssen, T. and Wilkins, R. (2019), "Strategies for increasing allied health recruitment and retention in Australia: a rapid review", Services for Australian Rural and Remote Allied Health (SARRAH), pp. 1-54, available at: https://sarrah.org. au/system/files/members/rapid_review_-_recruitment_and_retention_strategies_-_final_web_ ready.pdf (accessed 4 April 2020).

Bell, E. (2011), “Creating 'the rural pathway': Australia's university departments of rural health and rural clinical schools", International Journal of Child Health and Human Development, Vol. 4 No. 1, pp. 135-144.

Busetto, L., Luijkx, K., Calciolari, S., González Ortiz, L. and Vrijhoef, H.J.M. (2018), "Barriers and facilitators to workforce changes in integrated care", International Journal of Integrated Care, Vol. 18 No. 217, pp. 1-13, doi: 10.5334/ijic.3587.

Buykx, P., Humphreys, J., Wakerman, J. and Pashen, D. (2010), "Systematic review of effective retention incentives for health workers in rural and remote areas: towards evidence-based policy", Australian Journal of Rural Health, Vol. 18 No. 3, pp. 102-109.

Cosgrave, C. (2020), "The whole-of-person retention improvement framework: a guide for addressing health workforce challenges in the rural context", International Journal of Environmental Research and Public Health, Vol. 17 No. 8, p. 2698.

Cosgrave, C., Maple, M. and Hussain, R. (2018), "An explanation of turnover intention among earlycareer nursing and allied health professionals working in rural and remote Australia: findings from a grounded theory study", Rural and Remote Health, Vol. 18 No. 3, p. 4511, available at: https://www.rrh.org.au/journal/early_abstract/4511.10.22605/RRH4511 (accessed 31 March 2020).

Cosgrave, C., Malatzky, C. and Gillespie, J. (2019), "Social determinants of rural health workforce retention: a Scoping review", International Journal of Environmental Research and Public Health, Vol. 16 No. 3, p. 314.

Dawda, P. (2019), "Integrated healthcare: the past, present and future", Integrated Healthcare Journal, Vol. 1, e000001, doi: 10.1136/ihj-2019-000001.

Durey, A., Haigh, M. and Katzenellenbogen, J.M. (2015), "What role can the rural pipeline play in the recruitment and retention of rural allied health professionals?", Rural and Remote Health, Vol. 15, p. 3438, available at: www.rrh.org.au/journal/article/3438.

Fitzpatrick, S.J., Perkins, D., Handley, T., Brown, D., Luland, T. and Corvan, E. (2018), "Coordinating mental and physical health care in rural Australia: an integrated model for primary care settings", International Journal of Integrated Care, Vol. 18 No. 219, pp. 1-9, doi: 10.5334/ ijic.3943.

Geyman, J., Hart, G., Norris, T., Coombs, J. and Lishner, D. (2008), "Educating generalist physicians for rural practice: how are we doing?”, The Journal of Rural Health, Vol. 16 No. 1, pp. 56-80.

Hancock, C., Steinbach, A., Nesbit, T., Adler, S. and Aeurswald, C. (2009), "Why doctors choose small towns: a developmental model of rural physician recruitment and retention", Social Science and Medicine, Vol. 69, pp. 1368-1376. 
Henry, J.A., Edwards, B.J. and Crotty, B. (2009), "Why do medical graduates choose rural careers? rural and remote health", Vol. 9, No 1, p. 1083, available at: www.rrh.org.au/journal/article/1083 (accessed 8 March 2020).

Humphreys, J., Chisholm, M. and Russell, D. (2010), Rural Allied Health Workforce Retention in Victoria: Modelling the Benefits of Increased Length of Stay and Reduced Staff Turnover, Victorian Department of Health, Melbourne.

Humphreys, J., Wakerman, J., Pashen, D. and Buykx, P. (2009), "Retention strategies and incentives for health workers in rural and remote areas: what works?", available at: http://aphcri.anu.edu.au/ projects/network/retention-strategies-and-incentives-health-workers-rural-and-remote-areaswhat (accessed 12 April 2020).

Humphreys, J.S., McGrail, M.R., Joyce, C.M. and Kalb, G. (2012), "Who should receive recruitment and retention incentives? Improved targeting of rural doctors using medical workforce data", Australian Journal of Rural Health, Vol. 20 No. 1, pp. 3-10.

Humphreys, J.S., Wakerman, J., Wells, R., Kuipers, P., Jones, J.A., Entwistle, P. and Harvey, P.J. (2007), Improving Primary Health Care Workforce Retention in Small Rural and Remote Communities: How Important Is Ongoing Education and Training? Canberra ACT 0200, Australian Primary Health Care Research Institute.

Lynch, M. (2003), "Easy entry-gracious exit: testing new models for doctor recruitment and retention in chronically underserviced rural communities", Paper Presented at the 7th National Rural Health Conference, Hobart.

Martiniuk, A., Colbran, R., Ramsden, R., Edwards, M., Barret, E., O’Callaghan, E., Bullock, R., Lowe, E., Karlson, D., Curnow, J. and Gotch, B. (in press), "Capability... what's in a word? rural doctors network of New South Wales Australia is shifting to focus on capability of rural health professional", Rural and Remote Health, Vol. 20 No. 3, doi: 10.22605/RRH5633.

May, J. (2015), "Clinical service integration: a stocktake of the Australian experience", Future Hospital Journal, Vol. 2 No. 2, pp. 142-146.

McGrail, M.R. and Humphreys, J.S. (2009), "Geographical classifications to guide rural health policy in Australia”, Australia and New Zealand Health Policy, Vol. 6 No. 28, pp. 1-7.

McGrail, M.R. and Humphreys, J.S. (2015), "Geographical mobility of general practitioners in rural Australia”, Medical Journal of Australia, Vol. 203 No. 2, pp. 92-96.

New South Wales Rural Doctors Network (2003), Easy Entry, Gracious Exit, NSWRDN, Newcastle, 2003, available at: https://www.nswrdn.com.au/site/index.cfm?display $=401217$ (accessed 31 March 2020).

New South Wales Rural Doctors Network (2018), Health Workforce Needs Assessment Summary Report 2017-2018, Report for Commonwealth Government, available at: https://www.nswrdn. com.au/site/needs-assessment (accessed 29 June 2020).

New South Wales Rural Doctors Network (2019), Health Workforce Needs Assessment Summary Report 2018-2019, Report for Commonwealth Government, available at: https://www.nswrdn. com.au/site/needs-assessment (accessed 31 March 2020).

Norris, T. (2005), "The universal importance of the 'pipeline", Australian Journal of Rural Health, Vol. 13, pp. 203-214, doi: 10.1111/j.1440-1584.2005.00712.x.

One Geology (2019), "Meandering rivers", available at: http://www.onegeology.org/extra/kids/ earthprocesses/meanderingRivers.html (accessed 22 February 2020).

Queensland Health (2017), Advancing Rural and Remote Service Delivery through Workforce: A Strategy for Queensland 2017-2020, Published by the State of Queensland (Queensland Health), pp. 1-32.

Richards, H.M., Farmer, J. and Selvaraj, S. (2005), "Sustaining the rural primary healthcare workforce: survey of healthcare professionals in the Scottish highlands", Rural and Remote Health, Vol. 5 No 1, p. 365, available at: www.rrh.org.au/journal/article/365 (accessed 25 February 2020). meandering stream of rural life and career 
JICA 30,5

92

Russell, D.J., McGrail, M.R. and Humphreys, J.S. (2017), "Determinants of rural Australian primary health care worker retention: a synthesis of key evidence and implications for policymaking", Vol. 25 No 1, pp. 5-14.

Rygh, E. and Hjortdahl, P. (2007), "Continuous and integrated health care services in rural areas. A literature study", Rural and Remote Health, Vol. 7 No. 3766, pp. 1-10.

Schuurman, F., Shimizu, Y., Iwasaki, T. and Kleinhans, M.G. (2016), "Dynamic meandering in response to upstream perturbations and floodplain formation”, Geomorphology, Vol. 253, pp. 94-109.

Stein, K.V. (2016), "Developing a competent workforce for integrated health and social care: what does it take?", International Journal of Integrated Care, Vol. 16 No. 49, pp. 1-3, doi: 10.5334/ijic.2533.

Wakerman, J., Humphreys, J., Wells, R., Kuipers, P., Entwistle, P. and Jones, J. (2006), A Systematic Review of Primary Health Care Delivery Models in Rural and Remote Australia 1993-2006, Australian Primary Health Care Research Institute, Canberra, 2006, available at: http://www. anu.edu.au/aphcri/Domain/ PHCModels/Final_25_Wakerman.pdf (accessed 1 July 2020).

Wakerman, J., Humphreys, J., Russell, D., Guthridge, S., Bourke, L., Dunbar, T., Zhao, Y., Ramjan, M., Murakami,-Gold, L. and Jones, M. (2019), "Remote health workforce turnover and retention: what are the policy and practice priorities?", Human Resources for Health, Vol. 17 No. 99, pp. 1-8.

World Health Organisation (2010), Increasing Access to Health Workers in Remote and Rural Areas through Improved Retention: Global Policy Recommendations, WHO, Geneva, available at: http:// www.who.int/hrh/retention/guidelines/en/index.htm (accessed 31 March 2020).

\section{Corresponding author}

Robyn Ramsden can be contacted at: rgwaghorne@gmail.com

For instructions on how to order reprints of this article, please visit our website:

www.emeraldgrouppublishing.com/licensing/reprints.htm

Or contact us for further details: permissions@emeraldinsight.com 